\title{
Approaching the Ideal BLDC Motor: A Novel Electronic Speed Controller System for a Generator-Converted BLDC Motor with Field Weakening Feature
}

\author{
Hastanto SM Widodo ${ }^{2}$, Sarifuddin Madenda ${ }^{1}$, Suryadi Harmanto ${ }^{1} \&$ Lingga Hermanto $^{1}$ \\ ${ }^{1}$ Professor, Faculty of Computer Science and Information Technology, Gunadarma University, Indonesia \\ ${ }^{2}$ Doctoral Candidate, Faculty of Computer Science and Information Technology, Gunadarma University, \\ Indonesia \\ Correspondence: Hastanto SM Widodo, Doctoral Candidate, Faculty of Computer Science and Information \\ Technology, Gunadarma University, Indonesia
}

Received: February 10, 2020

Accepted: February 27, 2020

Online Published: February 28, 2020

doi:10.5539/mas.v14n3p90

URL: https://doi.org/10.5539/mas.v14n3p90

\begin{abstract}
The concept of an ideal Brushless DC (BLDC) motor which has adjustable rotor magnetic field offers an opportunity for wider BLDC area of implementation as a very versatile electric powerhouse especially in variable load areas such as on electric vehicle or other people movers. Characterized by its high-efficiency level, low maintenance and long service duration, the lack of physical commutation brush like in regular DC motor dictates the requirement of an electronic control system to regulates its commutation.

An electronic control system equipped with rotor field control capability in a collaboration with an ideal BLDC motor, is believed to offers wider implementation opportunity. Unlike a normal BLDC motor which has a standard power curved characterized with maximum power is only achievable in one specific speed, if properly controlled will have an adjustable maximum power in a wide range of rotational speed.

This study proposes a novel approach to an ideal BLDC implementation through novel electronic speed controller with rotor field control in addition to normal standard motor power control. As there is no such thing as an ideal BLDC motor at the current moment, an automotive generator which has an electromagnetic rotor is converted to become a BLDC motor as an effort to approach the ideal BLDC motor concept. Field weakening, the term used for adjusting rotor magnetic field in induction motor control, is adopted as the term for adjusting the BLDC rotor field in operation. Further, a novel an electronic control system is developed which special features to also control the rotor magnetic field.

The converted generator has been found to able to function like an ideal BLDC motor, by adjusting the electromagnetic rotor in its operation. It has been found to be able to provides maximum motor power within a wide range of rotational speed. Through rotor field adjustment, the converted generator provides a real-time versatile capability of allocating its power to either the high torque at low motor speed or to a very high speed at minimum torque. $39 \%$ to $81 \%$ operational efficiency levels have been achieved during the experiment, rendering the performance level of the converted generator and controller way above brushed DC motor and in par with most of standard BLDC motor.

The Field Weakening control has also been found to be useable for speed control. Further, a Proportional Integral close-loop speed regulation has also been developed for both motor and rotor control and was found to be able to works subsequently with seamless transition between each other.
\end{abstract}

Keywords: electronic speed controller, generator conversion into BLDC, field weakening

\section{Introduction}

Brushless DC (BLDC) motor has been the powerhouse behind many consumer goods which was previously not possible. Ranging from high power portable tools, electric bike or mobility scooter up to the latest electric powered small airplane. BLDC motors are proving to be very versatile motors as they can be used for these seemingly different uses. Many older handheld tools which were for the most part uses conventional DC brushed motor, these are being replaced by BLDC motors. 
Unlike the conventional Brushed DC motor, which uses a commutator brush, to regulates its commutation physically, BLDC requires an electronic control to be able to commutate and produce useable work. Those BLDC electronic control system is well known as Electronic Speed Controller (ESC).

Each BLDC motor design has its own peculiarities which make them desirable for particular applications. The BLDC motors used for motorized wheels for hand carts, trolleys and the like are likely designed to having high torque at low rotational speed. While on the other hand, BLDC used for fans and blowers are likely to be designed to have high rotational speed rather than torque.

For each BLDC motor, their characteristic will be highly dictated by the design, material and construction. Moreover, the BLDC works performance will also depend to the control quality provides by its electronic speed controller. In general BLDC motor power, torque and speed can be generalized by the following chart [AM. Harrington \& C Kroninger, 2013].

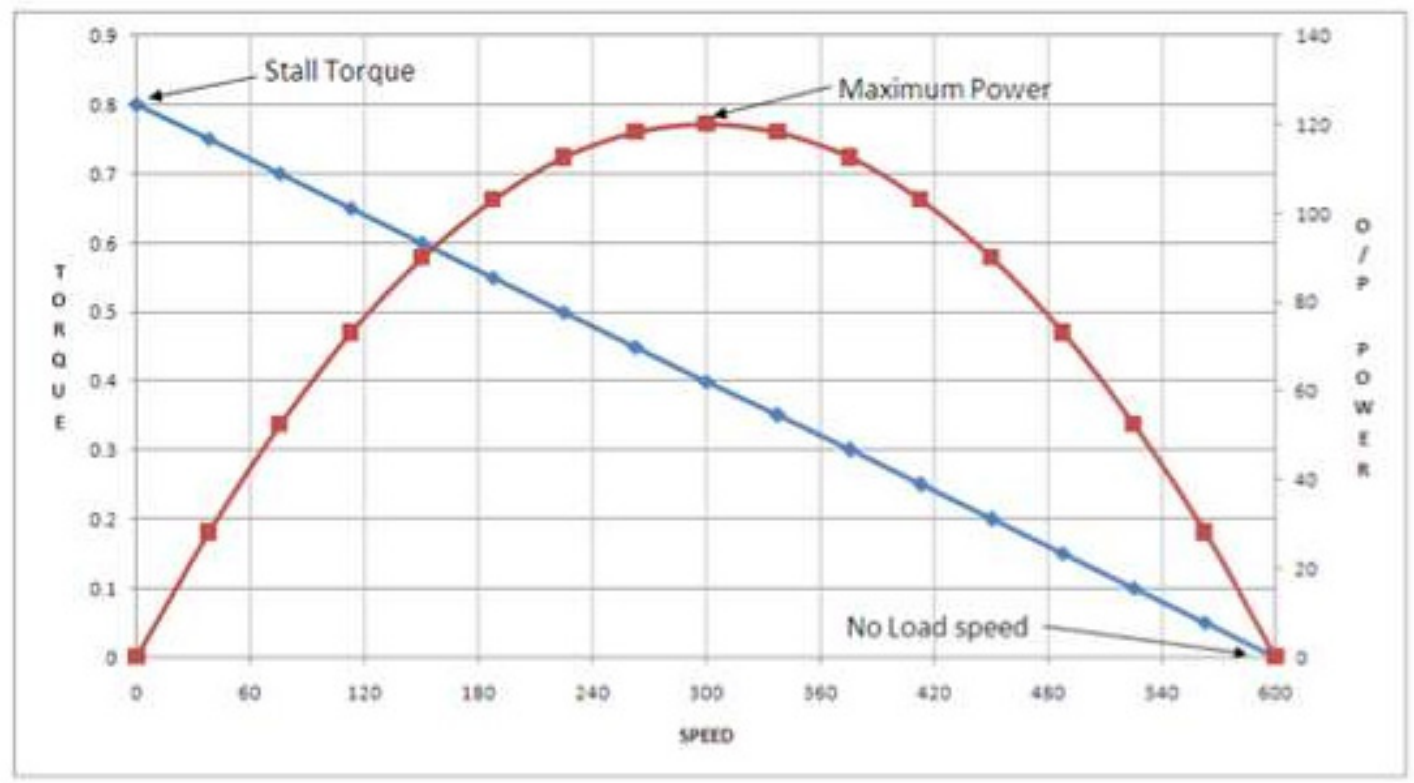

Figure 1. Speed-Torque-Power Curve [Pushek Madaan (2013)]

The power of a BLDC motor is defined as the cross product of torque and speed $(\omega)$ and theoretical will have a maximum torque at 0 speed and having 0 torque at maximum speed. Obviously, as power is a product of torque $(\tau)$ multiply by speed $(\omega)$ :

$$
\mathrm{P}_{\text {out }}=\tau . \omega
$$

Consequently, with a given Power $\left(\mathrm{P}_{\text {out }}\right)$, and a specific Torque $(\tau)$, the torque will diminish with the increase of rotational speed $(\omega)$, vice versa if the torque of the motor is increased during a motor operation, the rotational speed will decrease so that the total $\tau . \omega$ is equal with the given power. This condition is due to the fact that a BLDC motor is also producing electric current in the opposite direction while rotating which called as Back EMF. On the maximum rotational speed, the amount of Back EMF is almost equals with to the power supplied to motor, leaving only a small portion of energy enough for the motor to fight for frictional losses.

Therefore, the No-Load Speed characteristic or the maximum speed achieved by the BLDC without any load is one of the important motor characteristic as its reflects the point where the remaining torque left is only sufficient to rotate the rotor against its frictional losses. This fact has led to the condition whereas for every application of the BLDC motor, the importance of the appropriate motor selection for the designated power, torque and speed requirement is paramount.

\subsection{The Ideal Brushless DC Motor Concept}

While for specific power and speed requirement might be fulfils by the proper motor selection, it is not the case when the requirement is for a wide range of speed and power such as in electric vehicle direct motor application. The solution of adding mechanical gears to brings the speeds of the optimum power up or down to the desired 
levels will adds mechanical losses as added weight to the application. Further, opting for higher power motor option to cater the power requirement on the non-optimum speeds is also not cost effective.

The maximum speed of the BLDC is usually presented in $\mathrm{Kv}$ (or Kilo per volt) where represent the speed in thousand rotational per minute requires to produces 1 volt, or the maximum speed factor of the motor for every Volt of power supplied. Logically, two exactly the same BLDC motor equipped with different rotor magnet strength will surely perform differently as the one with stronger magnet will have lower $\mathrm{Kv}$ number compared with the weaker one. Because the stronger one will easily produce electricity in lower rotational speed compared to the weaker one, in the opposite direction, which will diminish the input current in lower rotational speed.

Wally Rippel, Principal Power Electronics Engineer in Tesla suggest [Rippel, Wally,2007] that in an ideal brushless motor, the strength of the magnetic field(B) produced by the permanent magnets in rotor, would be adjustable. When maximum torque is required at low speeds, the magnetic field strength should be set to maximum, so that motor currents could be maintained at their lowest possible values, and when torque levels are low on high speed, the B field should be reduced such that eddy and hysteresis losses due to B are also reduced. The technic of reducing the rotor magnetic field in induction motor control is quite common [Hong Zheng,Bo Wang,Wuqiao Luo 2013] and known as the field weakening technic.

Such ideal BLDC, with adjustable rotor magnetic field will easily satisfy the wide range power and speeds of many application, as the BLDC motor power curve is easily shaped by adjusting the rotor magnetic field strength. Unfortunately, there is no such thing as an ideal BLDC motor currently available. Nevertheless, the fact that a 3-phase generator is practically a 3-phase synchronous motor the same as BLDC except with variable rotor field for output voltage regulation [I Bodea 2005], offers an opportunity to develops a method to converts the easily available generator into a BLDC that approaches the ideal BLDC motor. The converted generator should have an adjustable rotor field strength through the same motor infrastructure currently being uses to regulate the output voltage. Automotive alternator, with its proven operational design of ruggedness and high rotational speed is a good candidate for the base of modification towards an ideal field adjustable BLDC motor.

Further, as a BLDC is meaningless without the electronic system to control the commutation process, the construction of a BLDC computer control system for the converted generator with field weakening is the major milestone to overcome for this endeavor. Having the advantages of vast selection generator in term of size, model and power rating that could be converted subject to the successful completion of this study, it is believed that the control system should be designed with the scalability in power rating as well as implementation in various generator design.

The raised of Integrated Power Module of Insulated Gate Bipolar Transistor (IPM IGBT), as an integrated power switching solution in a cost-effective, reliable and versatile package had open new possibility for a High-Power computer control system. As an advanced hybrid power device that combines high speed, low loss IGBTs with optimized gate drive and protection circuitry, its highly effective over-current and short-circuit protection is continuous monitoring of power device current making a high power implementation save enough computer control implementation. Those protection is further enforced by its over temperature and under voltage lock out protection system that enhanced its reliability further (Mitsubishi, 1996). Despite 1.7 Volt Vce saturation voltage compared to Mosfet On-Resistance, the fact that IGBT current and voltage handling capability is more suited to this implementation with regards to the power rating scalability.

Despite all the advantages of an IPM IGBT as a computer-controlled power switching devices, there are certain operational parameter that need to be followed strictly. One of very crucial parameter for IPM IGBT implementation, especially in bipolar PMW switching is their Arm shoot-through blocking time which was dictated to be at greater than $2.5 \mu \mathrm{S}$ (Mitsubishi, 1996). The Arm shoot-through blocking time parameter dictates how long a dead time should be imposed between two complementary PWM signal to assure that both High Side switch was completely turned off before switching to another state. Hastanto SM Widodo et al., proposed a Software based programmable IGBT IPM Dead-Time insertion module using 16-bit micro controller for BLDC motor control application with 3-phase Sinusoidal and Trapezoidal drive (Hastanto SM Widodo et al. 2020) well suited for the scalability factor in enabling other IPM IGBT implementation with different parameter.

\subsection{Previous Studies}

There are many scientific papers related to BLDC commutation control system [Liu Zhen, 2014], [Yasin Bektas, N. Fusun Oyman Sertelle, 2011], Huazhang Wang had discussed various aspect of design and implementation of Brushless DC Motor Drive and Control System [Huazhang WANG, 2011] while R.Babu Ashok, B. Mahesh Kumar, discussed Comparitive Analysis of BLDC motor for different control topology [R.Babu Ashok, B. Mahesh Kumar, 2017]. 
Despite there are studies related to field weakening technique in induction motor control [Waleed I. Hameed et. Al , 2016], [Hong Zheng, Bo Wang, Wuqiao Luo, 2013],[Jun Li, Qinruo Wang, Jiajun Yu, Jianbin Xiong, 2006],[ Calin Capitan, 2009], no studies of field weakening implementation in BLDC has been found. This study will contributes new understading in field weakening control characteristic in BLDC motor implementation.

\subsection{The Proposed Solution.}

This paper will propose a Novel Electronic Speed Controller System for a Generator-Converted BLDC motor with field weakening feature. For future scalability in power rating and various generator model, the proposed electronic speed controller design will utilize High Power IPM IGBT and external mountable hall sensor infrastructure. This paper will also propose a viable generator to motor conversion method for Bosch 100A automotive generator.

The remainder of this paper is structured as follows, the section 2 will discuss the approach of converting an automotive generator into a BLDC motor with adjustable rotor field followed by a sub section that discuss the novel speed controller design and construction. Section 3 will discuss the performance characteristic of the motor as well as the controller speed regulation performance and discussion. Conclusion and future research recommendation will be discussed in section 4 .

\section{Generator Conversion \& Novel Speed Controller with Field Weakening Feature}

As currently there are no such thing as an ideal BLDC motor, an approach by converting an automotive generator into a BLDC with an adjustable rotor is chosen. Further, due to rotor high rotor mass and inertia of an automotive generator, a special approach was taken for the commutation method. As suggested by Lee, S., Lemley, T., \& Keohane, G., in order to assure smooth computational result without torque ripple a sinusoid drive mode is implemented for low rotational speed and followed by trapezoidal drive mode subsequently to enable higher rotational speed [Lee, S., Lemley, T., \& Keohane, G. (2009)].

Implemented with Mitsubishi PM150CSD060 IPM IGBT with 150 Ampere current handling capability and $600 \mathrm{~V}$ voltage handling capability, the design also implement the Software based programmable IGBT IPM Dead-Time insertion module for BLDC motor control application with 3-phase Sinusoidal and Trapezoidal drive (Hastanto SM Widodo et al. 2020) using 3 Arduino Promini as the interface between the speed controller and the IPM IGBT module.

Further, as the control system is targeted to works with varying rotor field strength with the consequences for nonstandard back EMF signal, the control system will be based on a sensored commutation process which requires the installation of 3 hall sensor separated by 120 degrees in order to be able to operated.

\subsection{Automotive Generator Conversion}

The automotive generator is practically a 3-phase synchronous generator/motor with integrated high power rectifier installed. Hence, the first logical steps of converting it to a 3-phase motor is by removing the rectifier block at the back end of generator. The removal of rectifier block in Bosch 100 Ampere automotive generator has been found to be quite straight forward, just by unbolting the rectifier block and cutting the connection of 6 wires from all 3-phases coming out from the generator. Figures 2 points out all the disconnection point from the Bosch 100 Ampere Generator.

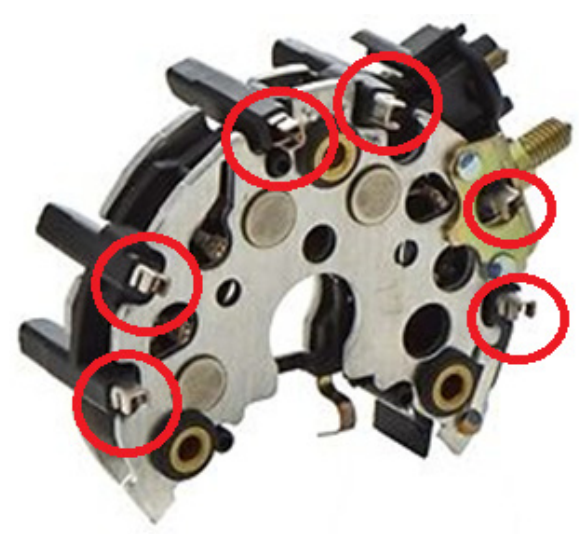

Figure 2. Rectifier block and the disconnection point 
With a standard multi-tester, we could then verify that every two wires close to each other is belonging to the same phase by checking the continuity of those two wires. Once confirmed all wired then could be connected either as a star or delta configuration.

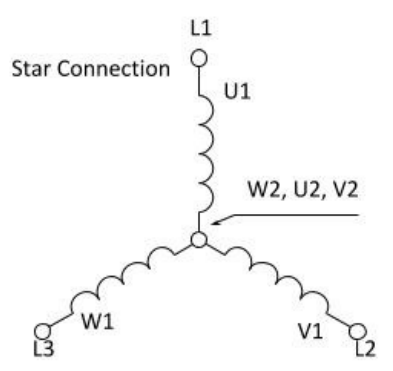

Terminal Connections
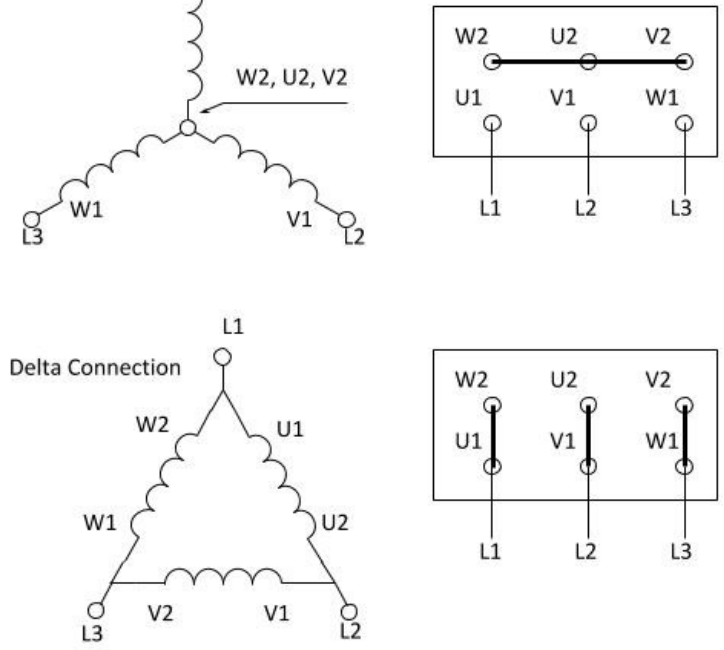

Figure 3. Star and Delta connection configuration [I Boldea (2005)]

Once the connection is made, the previously an automotive generator is now becoming a 3-phase motor which unfortunately with zero magnetic field rotor. In order to finalized the conversion, the existing voltage regulator brush infrastructure need to be re-wired to be used as the rotor coil supply line through the existing slip ring.

Further, a means of a 120 degree separated hall sensor detecting a magnet wheel with 12 interchanged pole for representing 6 rotor pole of Bosch 100 Ampere Generator needs to be implemented. In this study, a PETG 3D printed magnet wheel and sensor housing has been developed and implemented as shown in figure 3 .

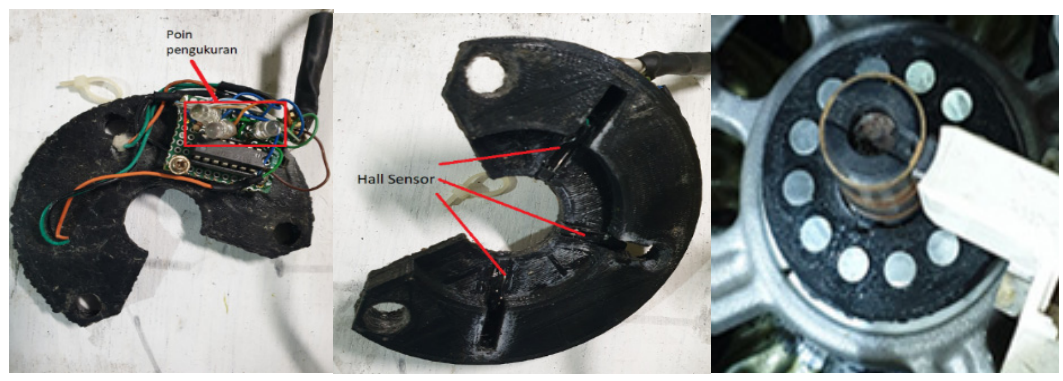

Figure 4. Hall Sensor and Magnet Wheel

The final product of this conversion, as shown from the back of the converted motor, is consisting of a phase connection in a delta configuration, the rotor supply infrastructure which utilizing rotor slip ring and regulator's brushes and the last one is the installed sensor plate and magnet well. Figure 4. shows the backend part of the converted rotor. 


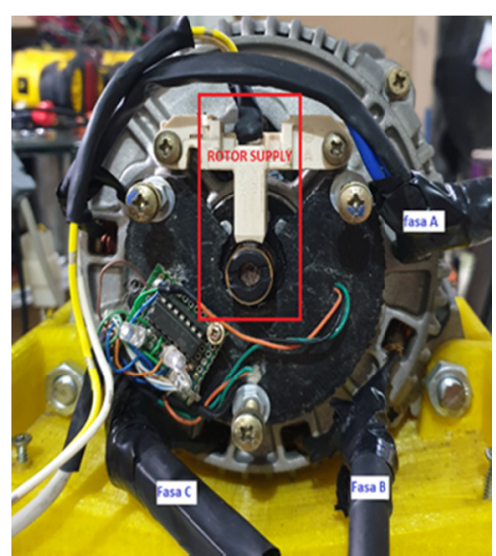

Figure 5. The Back end of the converted Rotor Phase A, B \& C labelled as Fasa A, B \& C

Due to the miss-alignment might occur of the installed magnet and sensor with regards to the motor pole a special calibration tools and procedure has been developed. The miss-alignment data as the result of the calibration process is later are uses during the commutation process.

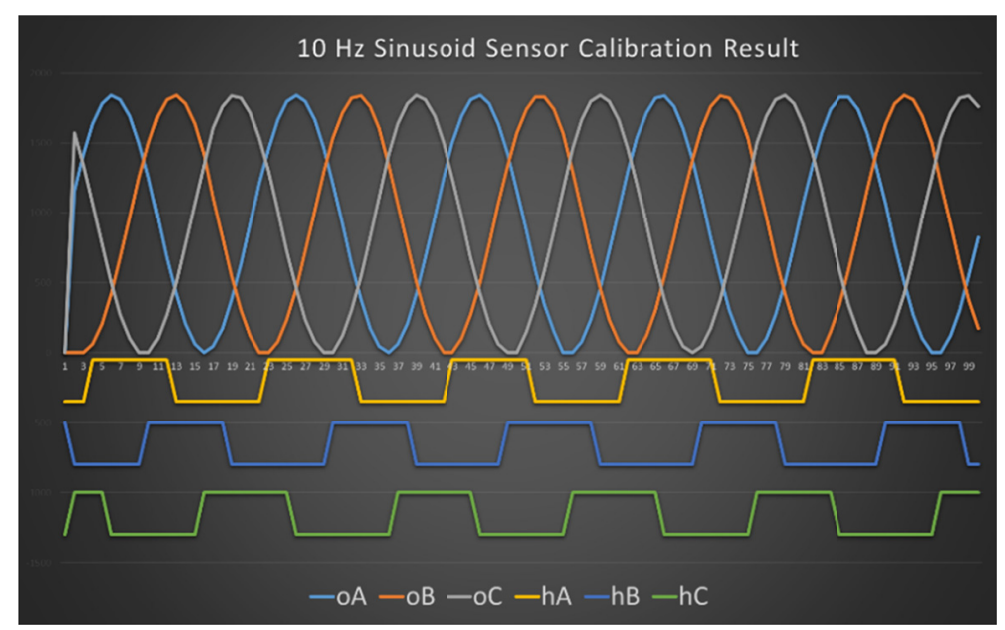

Figure 6. Hall Sensor Calibration Result

The Sensors are calibrated by producing 3-120 degree spaced sinusoid while registering all hall sensor reading. A $10 \mathrm{~Hz}$ sinusoid was generated from 120 points per period sinusoid static map, and sensor miss alignment then recorded whereas in this condition is that hall sensor transition state is at point 40 of the sinusoid static map index.

\subsection{Novel Speed Controller Design and Construction.}

For higher speed controlling function capability, Teensy $3.5120 \mathrm{MHz}$ arm-cortex was selected. Benefited from ARM hardware-based interrupt processing capability, the Interrupt driven Trapezoidal drive enjoys faster interrupt handling capability of ARM design. Further, a serially connected Human Machine Interface (HMI) also used for various aspect of user control as well as a visual representation of motor performance as well as other informational data.

The hardware diagram block of the system is as shown in figure 7 


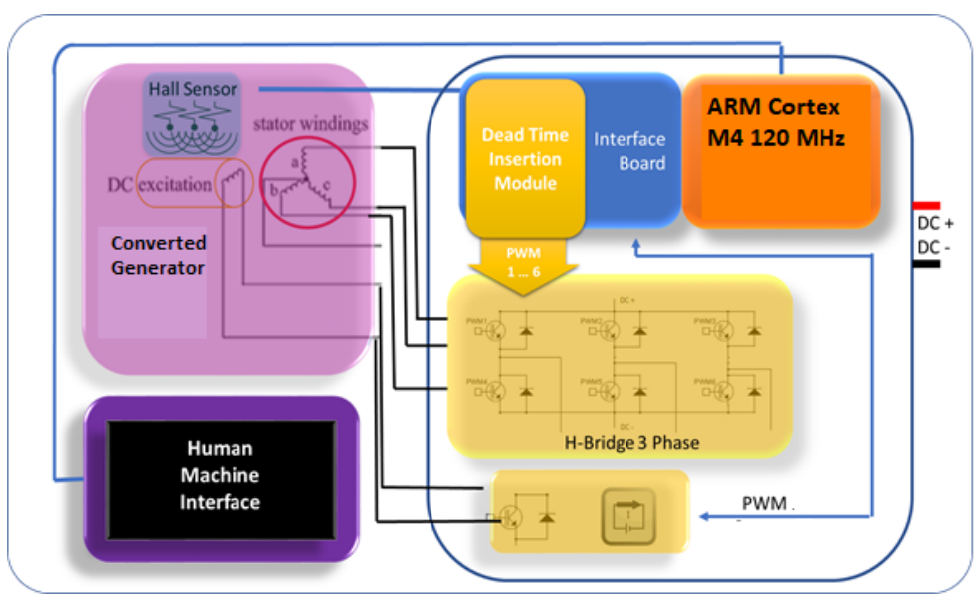

Figure 7. Diagram block of the System

Figures 7. shows a clear separation between the components and the modularity of the micro-controller, the interface board, HMI and the power switching infrastructure. With such modularity and clear separation, the future scalability of such system could be assured.

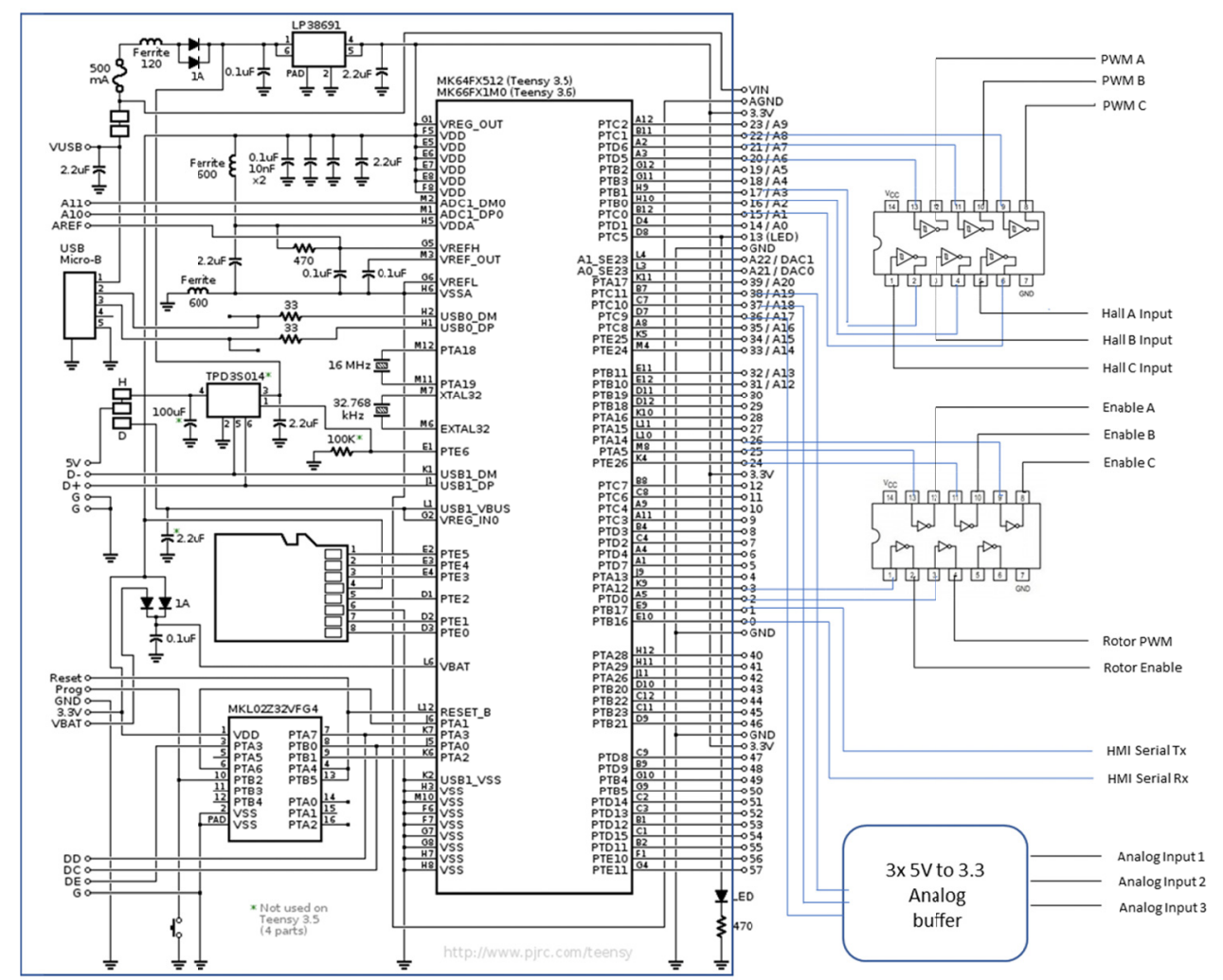

Figure 8. Circuit Diagram of the main controller and Interface board

The main controller of Teensy 3.5 and interface board is shown in figure 8. 74LS14 Schmitt trigger is used for hall sensor interface for added noise immunity. While on the output driving side a 74LS07 high voltage open-collected buffer was selected to allow wider future expansion for implementation with different power switching signaling requirement. As the Teensy analog input is not $5 \mathrm{~V}$ compliant, an analog voltage divider with rail-to-rail 3.3 Volt op-amps buffer is implemented for assuring micro-controller operational safety.

The controller software was written in TeensyDuino 1.44 using Arduino IDE 1.8.7. The selection of Arduino IDE 
as the development framework will contributes to effortless portability of the software to other future more powerful micro-controller. The implementation of Graphical Human Machine Interface also has been found to expedite the learning process for understanding the characteristic of the converted motor through graphics visualization of sensor data as well as the driving power of the motor.

Figure 9 shows how the designed HMI was still able to operate in the highest unloaded motor operation of 11.257 electrical RPM.

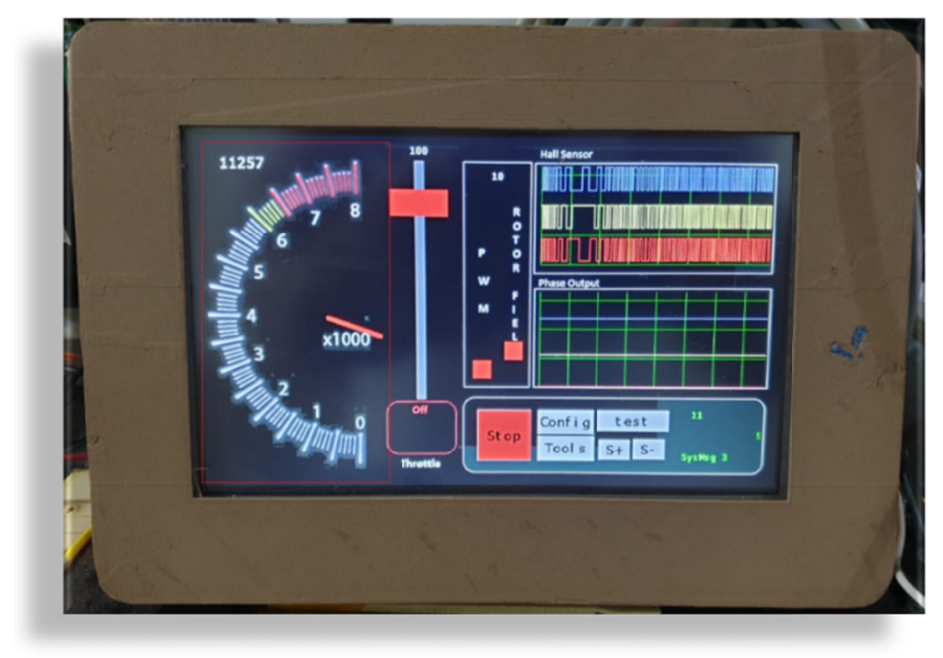

Figure 9. HMI display in the highest unloaded motor operation

As the main controller function is to handle the commutation process of the motor, special care has been implemented to assure all serial communication event between the controller and HMI was executed with lower priority through batch semaphoring technique. Remote command execution from HMI was also assured through a command state control and confirmation, assuring that all the command state and submission is in sync between HMI and the main processor.

In the heart of its operation, the speed controller utilizes Sinusoidal commutation method during start-up and low- speed operation and switch to trapezoidal ones with seamlessly and vice versa. The transition of both methods of operation was implemented by replacing the interrupt handler of every Hall event changes specifically tailored for each commutation method. The following codes dictates how both commutation method switching was implemented.

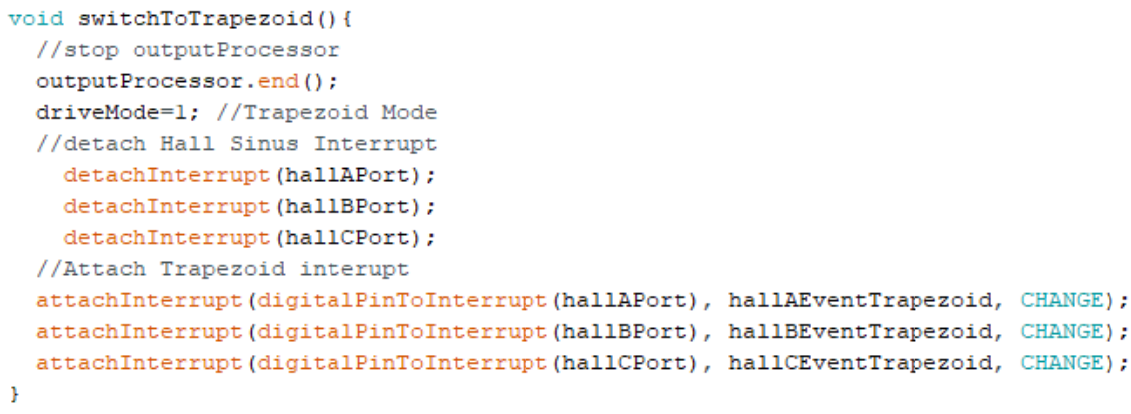




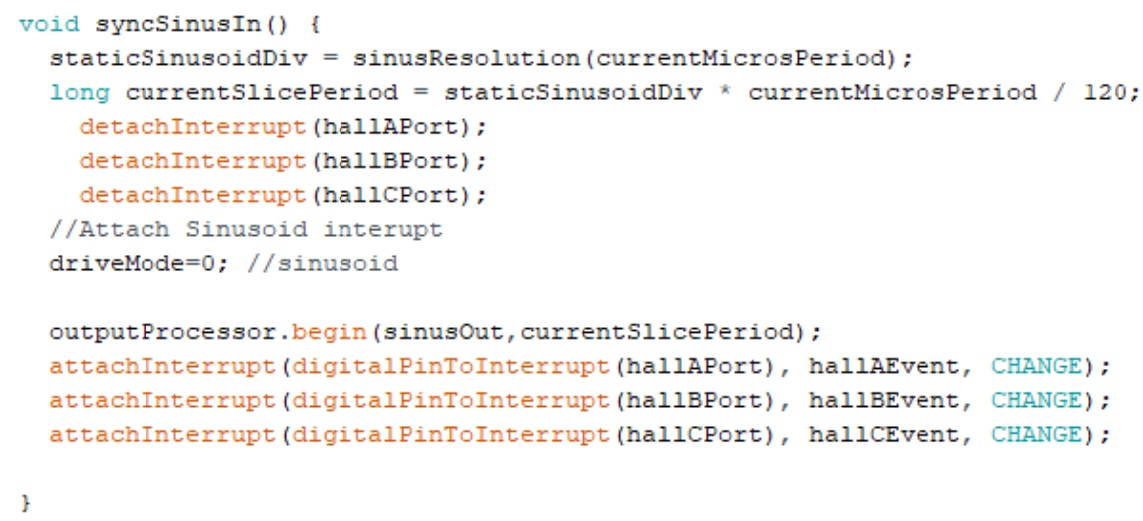

As it could be seen from the code above, the trapezoid commutation mode was strictly governed by 3 Hall Event procedure. While on the sinusoid was a bit more complex due to the fact that the generated sinusoid was produces by the ouputProcessor background process and the Hall interrupt event was merely a synchronization point of the sinusoid produce and the exact rotor position. With a Digital Storage oscillator, we could easily verify the PWM signal produced for both commutation methods. Figure 10 shows two PWM phases in a 120-degree separation of the sinusoid commutation and two PWM complementary gate driver in a trapezoid mode,

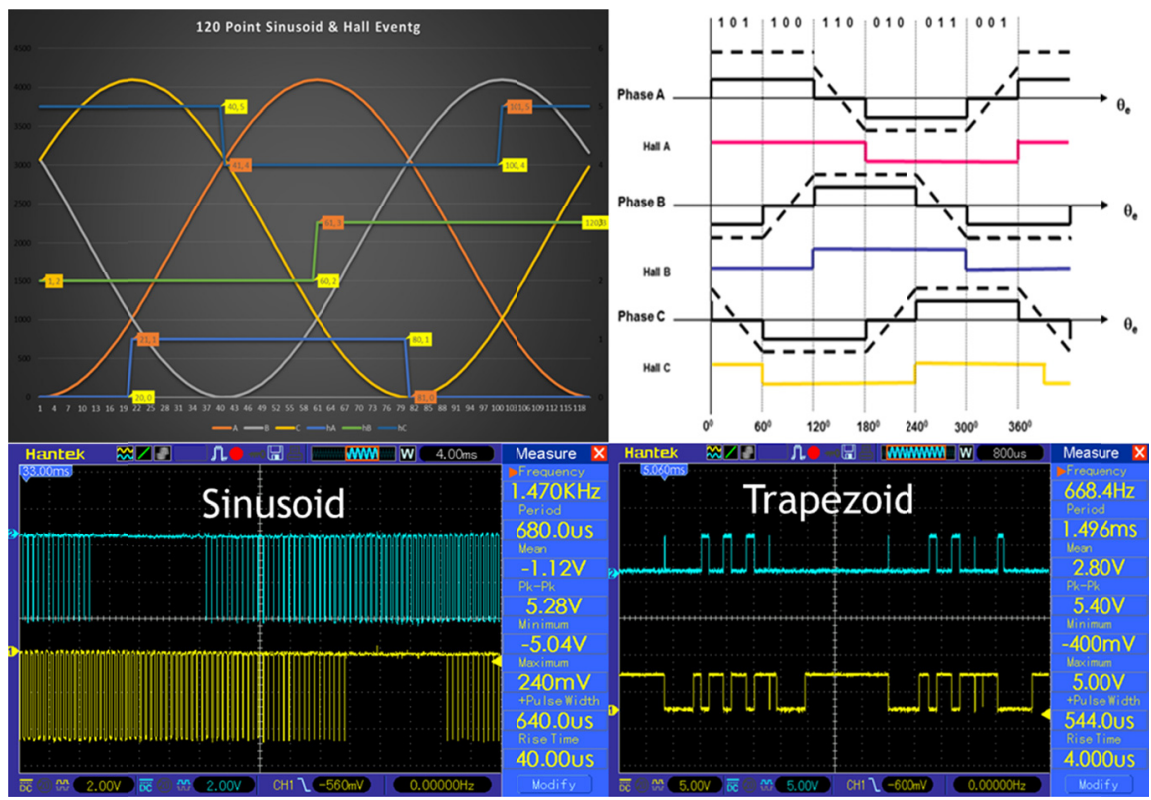

Figure 10. 2 Phase Sinusoid commutation and Complementary PWM in one Phase for trapezoid with its hall event mapping point

Further, the system also provides two type of speed regulation method, an open loop control whereas the throttle and rotor field slider in HMI directly control the amount of power delivered, and the closed control one whereas either the rotor or motor amount of power was regulated by Proportional-Integral closed loop control to regulated the motor within the set targeted speed.

A conservative $\mathrm{Kp}$ and $\mathrm{Ki}$ for both Rotor and Motor regulation were chosen to accommodate motor characteristic variation due to changes in rotor magnetic field. For this study, to enable an almost real-time visualization in HMI both motor and rotor control still utilizing low $0-100$ integer resolution instead of the 12-bit resolution as was used in PWM generation. By having this the converted motor control behavior easily understood from the real-time visualization in HMI. 


\section{Result}

In order to measure the power generated power as well as providing a variable mechanical load for the converted motor, a same brand with bigger current producing capacity automotive generator is directly connected to the output shaft of the motor and will be referred further as the load generator. As the internal load generator voltage regulator will regulate their rotor magnetic field in order to provide a constant 14.7 Volt output, the torsional requirement of the load generator will vary for every rotational speed. This feature was utilized more by further loading the load generator output with various combination of electrical load using a series of configurable 50Watt@12V halogen lamps. The measurement of the consumed power by the motor and the power produced by the load generator is carried out using two independent watt meters.

The measurement of the power consumed and produce is the executed in motor power supply input and load generator output using a watt meter. The organization of the power measurement test bench is shown in figure 11 .

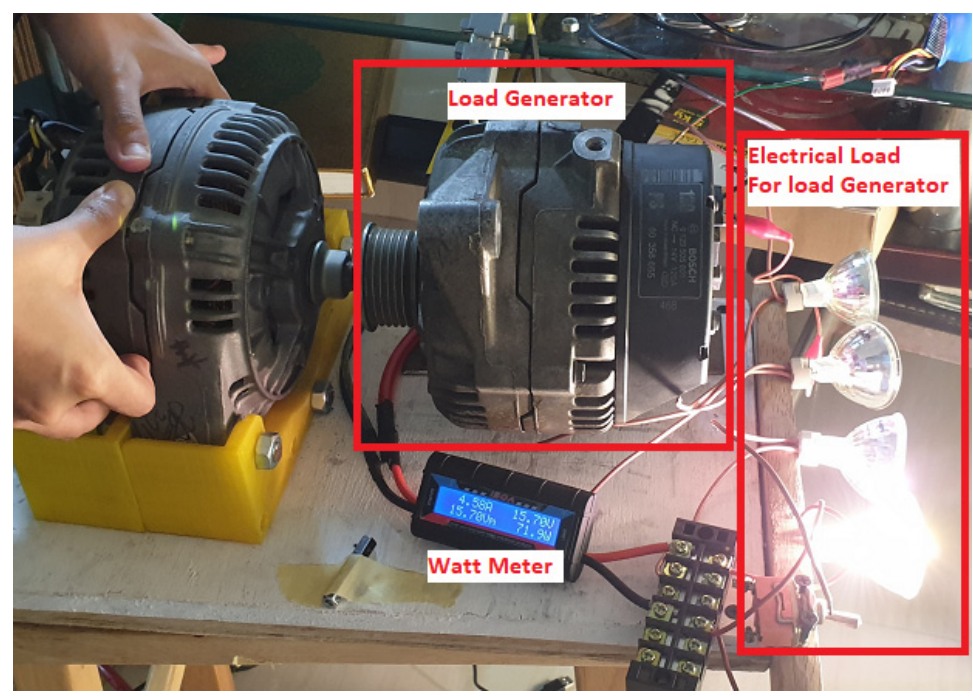

Figure 11. Motor power test bench

The measured output power will also constitute of load generator efficiency level and will be addressed as the effective total efficiency. Nevertheless, as the comparative data will used the same infrastructure of power generation, both motor and generator are assumed to have the same behavior in term of efficiency therefore the result data of the power generated with different speed is valid.

Motor Speed and PI control operation data measurement was provided by the controller through its logging capability. Logged data is later on dumped to the host computer using a serial communication for further processing.

\subsection{Converted Generator Performance and Characteristic}

The rotor magnetic control by means of producing variable rotor supply with PWM has been found to be working as designed. The chosen low PMW modulation of $488 \mathrm{~Hz}$ was shown able to produce designated output voltage and demonstrated by the linear current output for the whole area of operation. The magnetic field however are demonstrating the saturation effect as indicated by the significant immediate field density decrease with the increase of rotor current (Dura Magnetic 2020). Figure 3.1.1. shows the field density of the rotor with the increase of PWM duty cycle. 


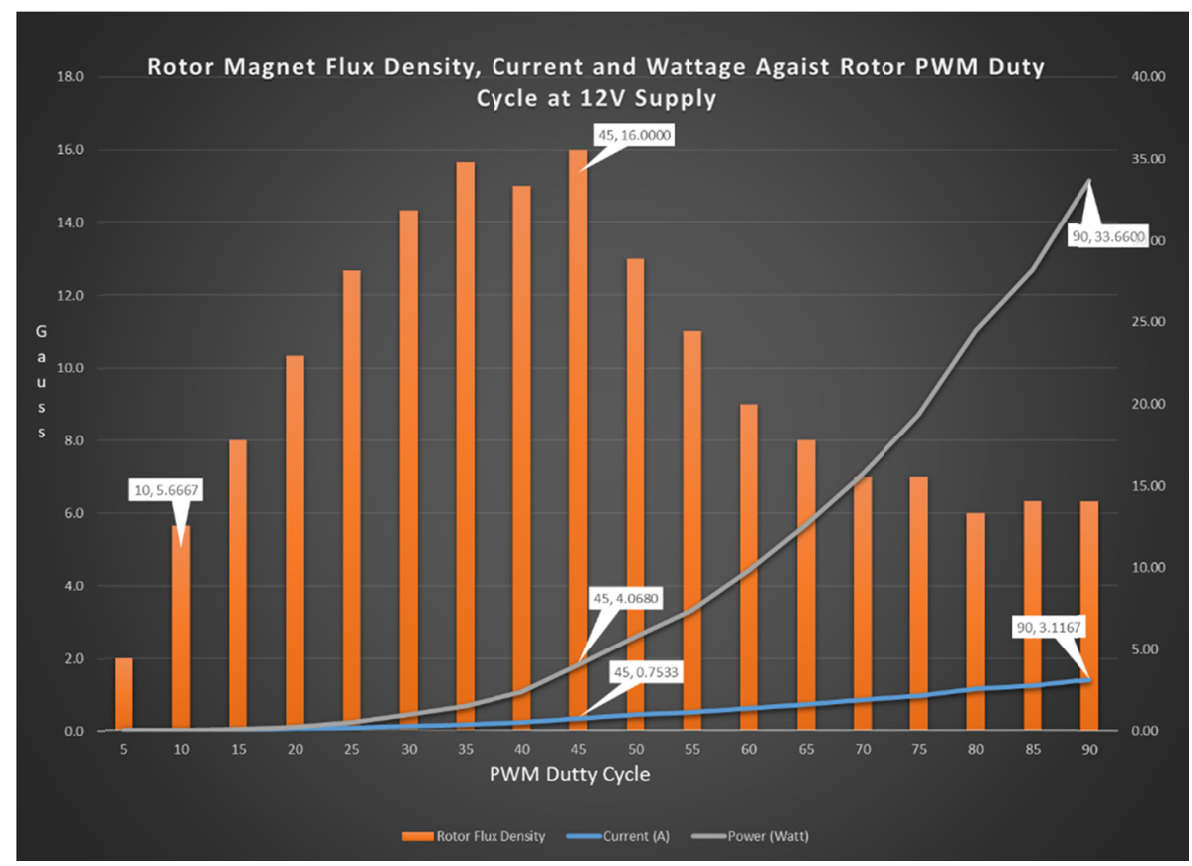

Figure 12. Rotor Magnet Flux Density, Current and Wattage against PWM Duty Cycle at 12V

With the exception of field density at $45 \%$ duty cycle, it was observed that the saturation effects were kicking in after $45 \%$ duty cycle in which point the rotor flux density is rapidly decreasing and stabilizing around 6 Gauss for duty cycle $80 \%$ and beyond. As the proportionality of the energy consumed to powering up the rotor against the generated flux density is not effective beyond $45 \%$, the control operating area of rotor field weakening is chosen between $10 \%$ to $45 \%$ PWM duty cycle with $12 \mathrm{~V}$ supply.

The effect of field weakening in the motor running in full power was found working as expected. With the increase of rotor magnetic flux due to the increase of the PWM duty cycle, the rotational speed of the motor also decreased proportionally. Figure 12. shows the relation of full power motor speed with various PWM duty cycle of rotor magnetic field.

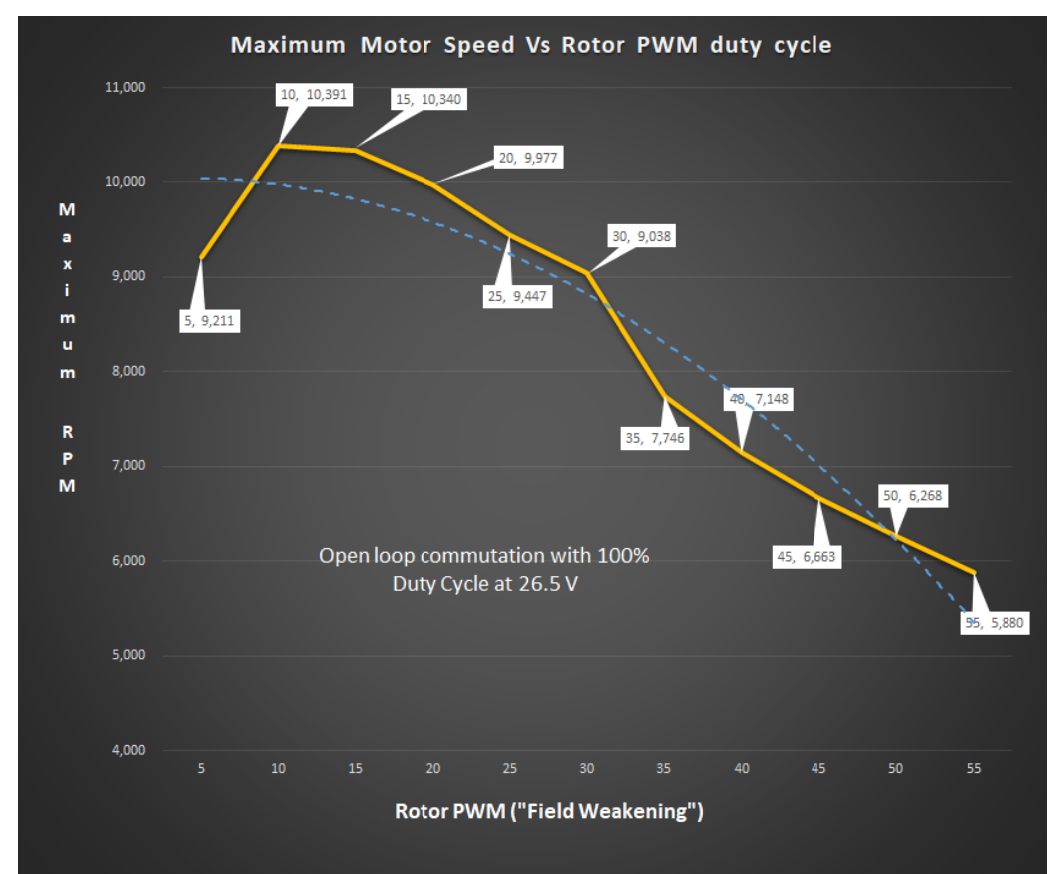

Figure 13. Maximum Motor Speed achieved Vs Rotor PWM Duty Cycle 
As it could be seen from figure 13. the moving average of measured speed shows a smooth linear decrease in within $10 \%$ and $45 \%$ duty cycle. The $5 \%$ duty cycle demonstrated a significant decrease in speed which more due to the insufficiency of rotor magnetic flux for proper operation. The area beyond $45 \%$ up to 55 was found to be performing with similar behaviors regardless of nonlinear power consumption for rotor field excitation as shown in previous figures.

The different maximum speed achievement for various rotor field scenario confirmed that the field weakening technic is working as expected. This also confirmed that the converted generator is behaving like an ideal BLDC motor up to a certain level.

Further, by measuring the power input and output of the said motor also confirmed that unlike other BLDC motor, the converted generator is able to produce the roughly the same amount of power within a wide range of rotational speed by adjusting the rotor magnetic flux through its PWM duty cycle. Figures 3.1.3 to 3.1.5 clearly shows this features in 3 different electrical load scenarios.

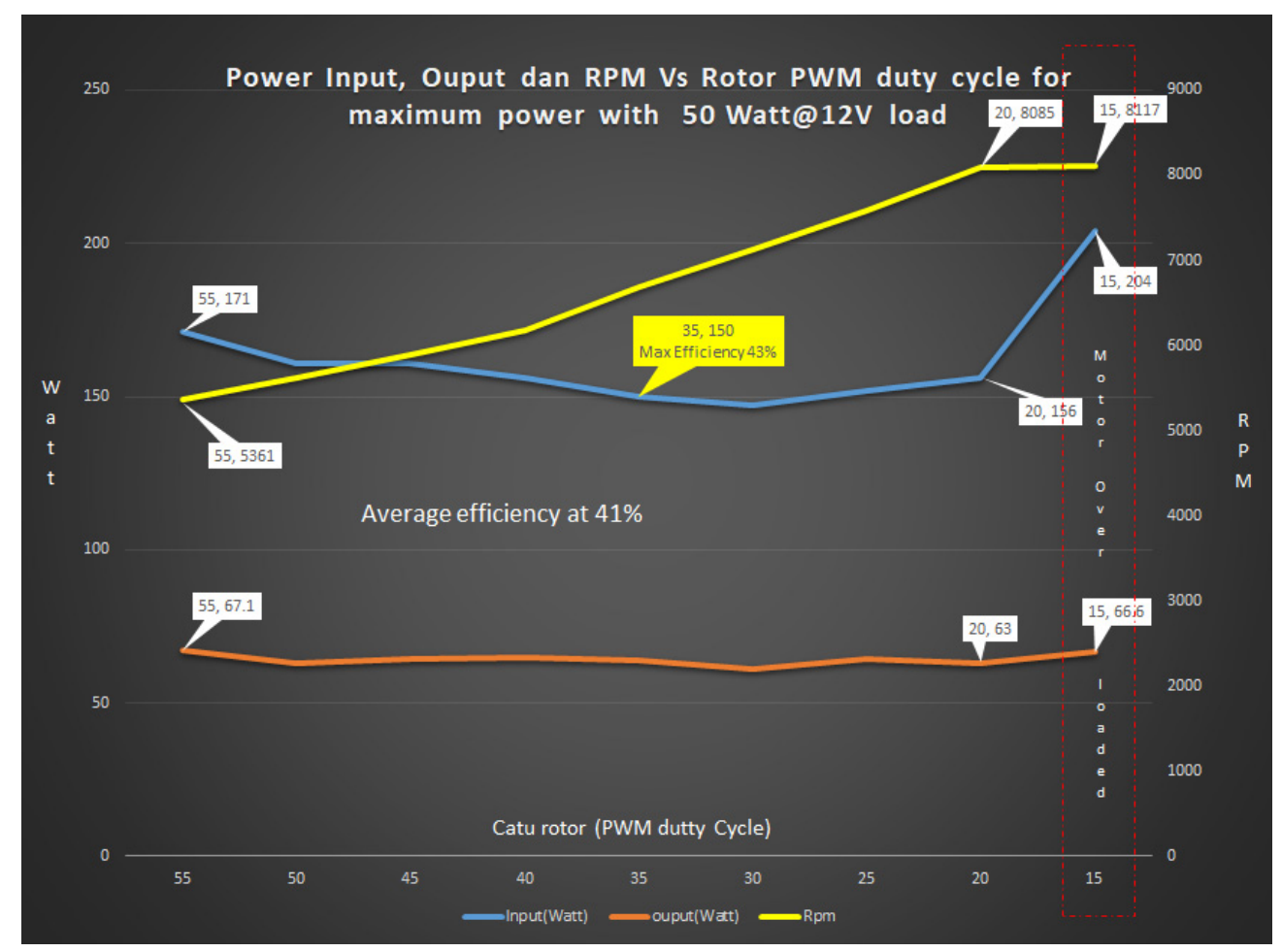

Figure 14. Power Input, Output and RPM vs Rotor PWM duty cycle for 50Watt@12V load 


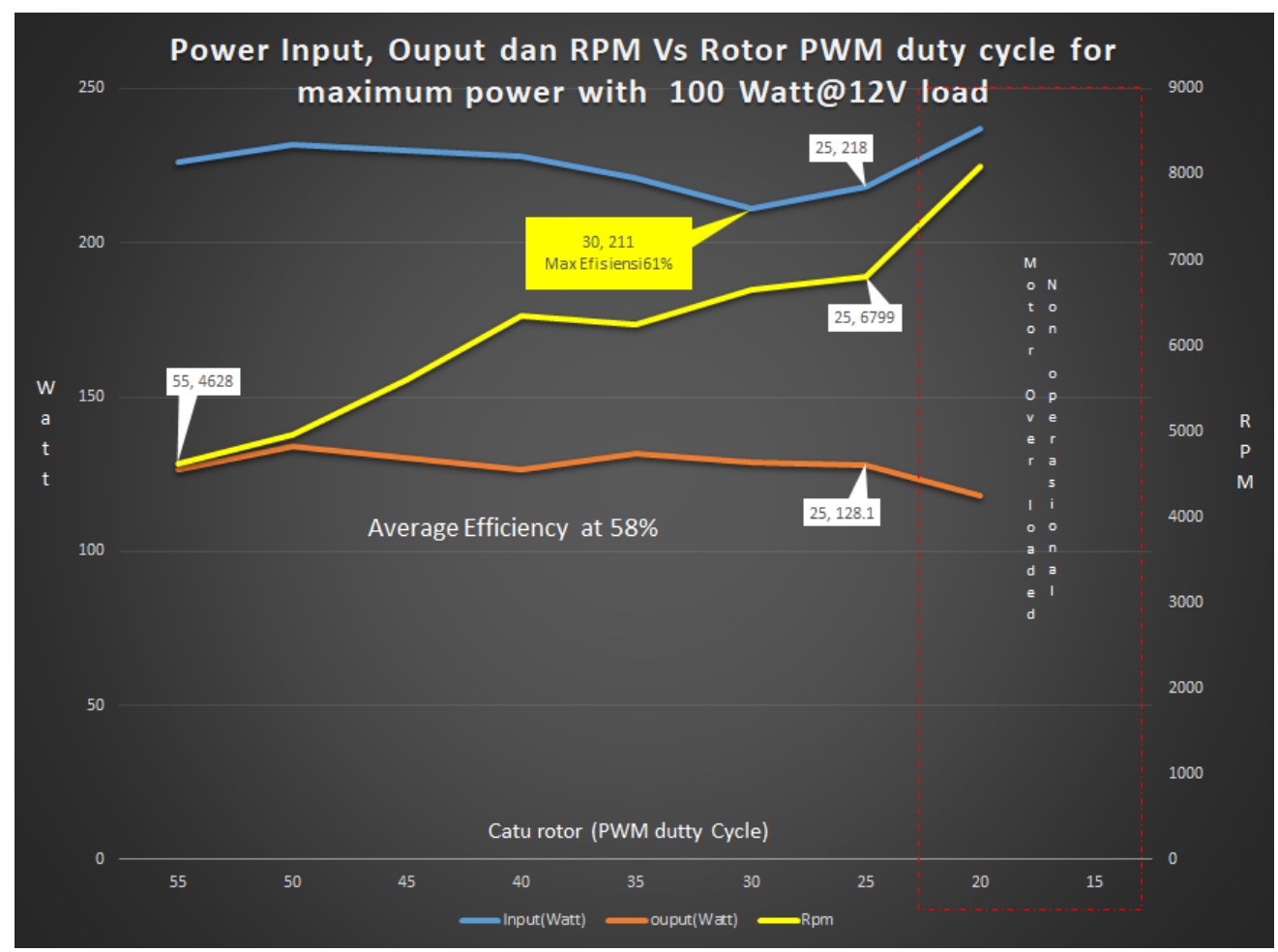

Figure 15. Power Input, Output and RPM vs Rotor PWM duty cycle for 100Watt@12V load

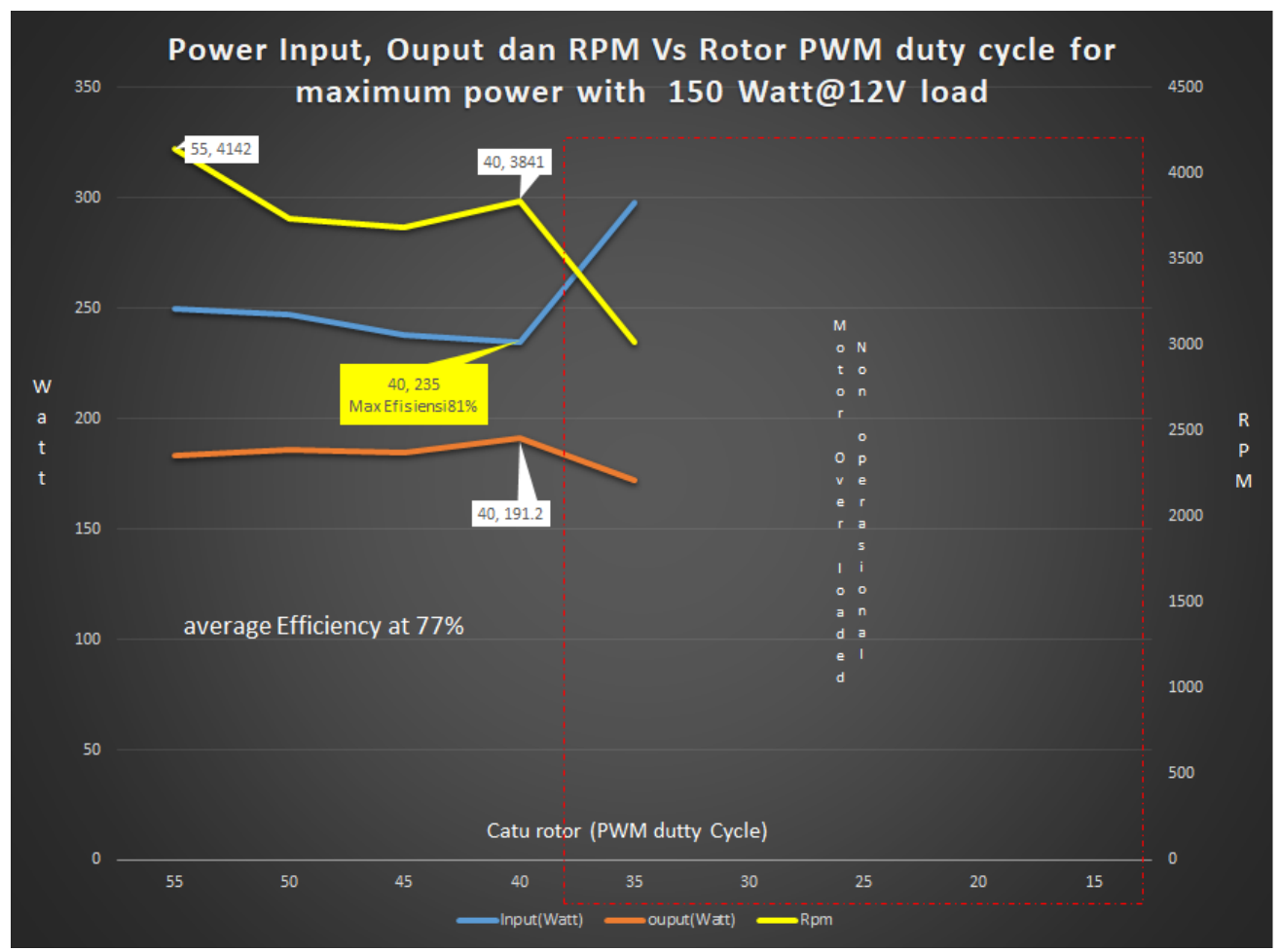

Figure 16. Power Input, Output and RPM vs Rotor PWM duty cycle for 150Watt@12V load

As in could be seen in figures 14. through 16, within normal operating range of the motor with constant power supply, the power produced relatively similar across wide range of rotational speed through different rotor field strength adjustment. Despite tighter working area due to different minimum flux density requirement for different load, the converted generator behaves consistently across different load. 
The efficiency achieved throughout 3 testing scenarios are in the range of $39 \%$ to $81 \%$, which apparently reflecting the area of various BLDC motor [AM. Harrington \& C Kroninger, 2013], with the highest efficiency achieved at the highest test load. Throughout the testing, it could be observed that despite with the fact that the motor is able to produce maximum power on wide range of rotational speed, the law of conservation of energy is still applied. The motor still follows the motor power formula with varying torque at different rotor field setting. Hence, we could safely that following the $\mathbf{P}_{\text {out }}=\boldsymbol{\tau} . \boldsymbol{\omega}$ motor power formula, that for BLDC rotor with the given the same amount of power output for the motor, varying $\boldsymbol{\tau}$ through field weakening method will change $\boldsymbol{\omega}$ or the motor rotational speed.

The Figures also shows that there are minimums field strength required for the motor to operation normally. Rotor field strength below the threshold point will bogs-down the rotor and put the motor into a Quadrant 4 operation which is a reverse breaking one with the consequences of increasing power consumption and decrease speed.

The fact that the converted rotor is able to produce maximum power within a wide range rotational speed is negating the normal BLDC motor characteristic whereas maximum power is bounded in one rotational speed only. Therefore, we could safely conclude that the converted generator is able to approach the proposed ideal BLDC operation through its field weakening.

\subsection{Proportional - Integral Speed Regulation}

Two Proportional-Integral close-loop speed regulation has been developed each utilizing either the motor power control or the rotor field control. A single conservative value of $\mathrm{Kp}$ and $\mathrm{Ki}$ chosen to regulates the changing characteristic of the converted motor has been found to works very well with multiple rotor field setting and able to adapt to different targeted speed in its operation. Figures 17. through 19. shows several scenarios in motor PI Performance with various rotor field setting and targeted speed.

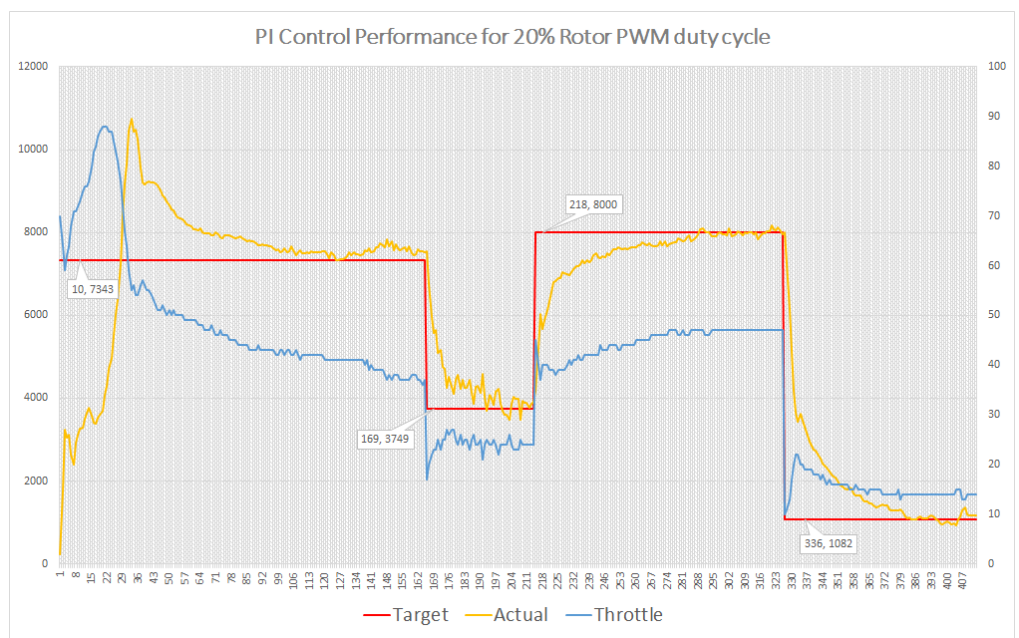

Figure 17. PI control performance for $20 \%$ Rotor PWM duty cycle 


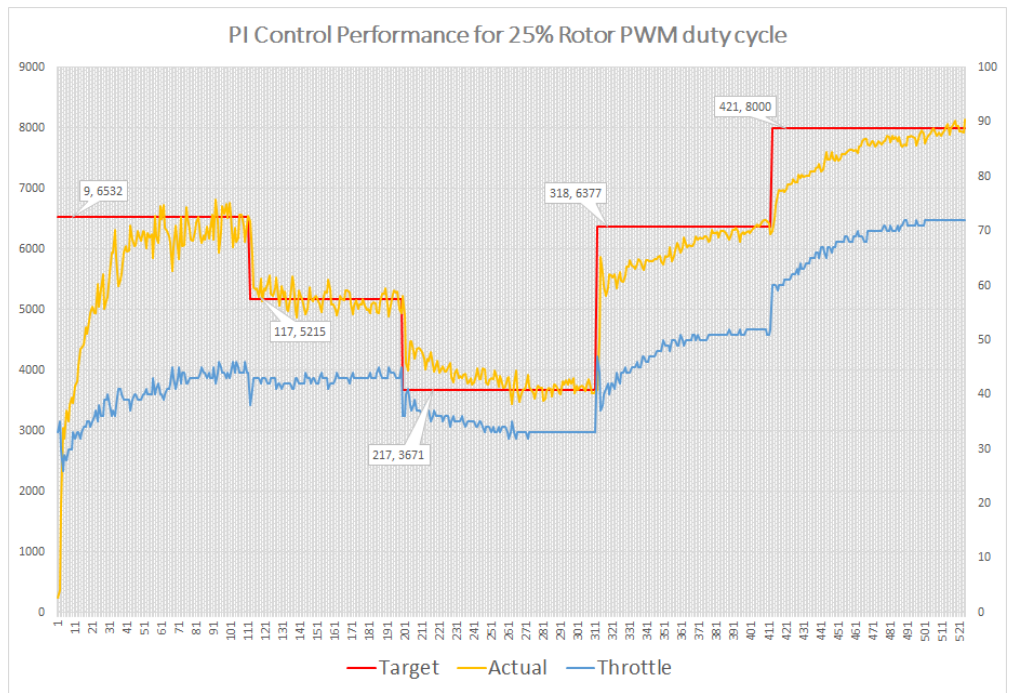

Figure 18. PI control performance for 25\% Rotor PWM duty cycle

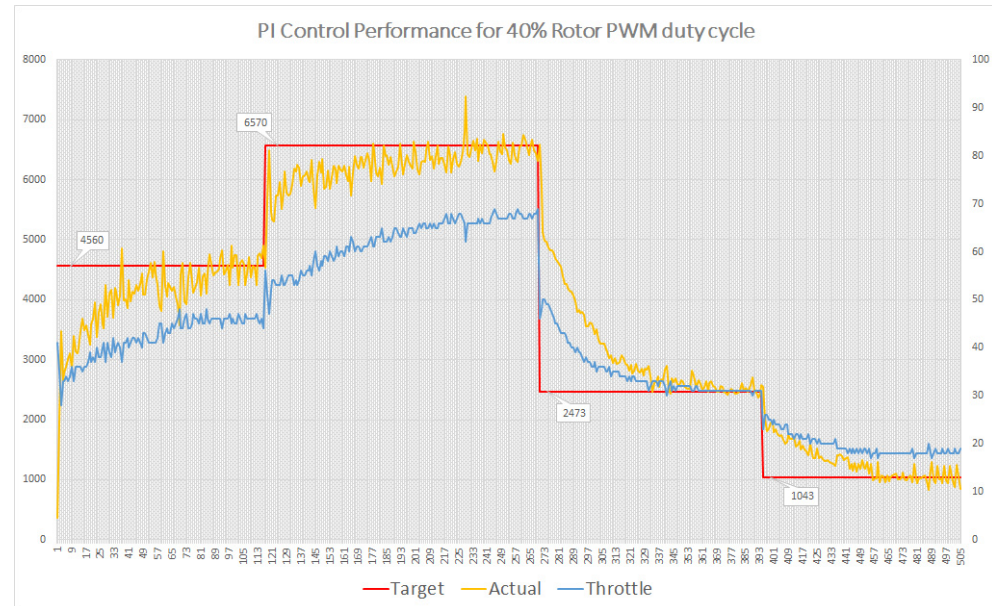

Figure 19. PI control performance for $40 \%$ Rotor PWM duty cycle

Further, the experiment of utilizing the field weakening control for speed regulation as an alternative for speed regulation through motor power has produces a promising result. The developed Proportional-Integral control loop for speed regulation by varying field weakening of the rotor field has shown to be able to regulate motor speed from standstill. Although there are significant over-shoots due to the implementation of minimum field weakening value for viable startup operation, the PI control is then able to regulate motor speed within the set targeted speed. A subsequent combined operation between PI rotor field regulation and PI motor power regulation had shown that the transition process between two- mode of control. Further, a test scenario is also expanded with disturbance in rotor field while on the motor power PI regulation and resulting that the developed motor power PI regulation is able to handle such disturbance. Figures 20. clearly shows the subsequent performance of the rotor field regulation method followed with motor power regulation method will acceptable result and smooth transition. 


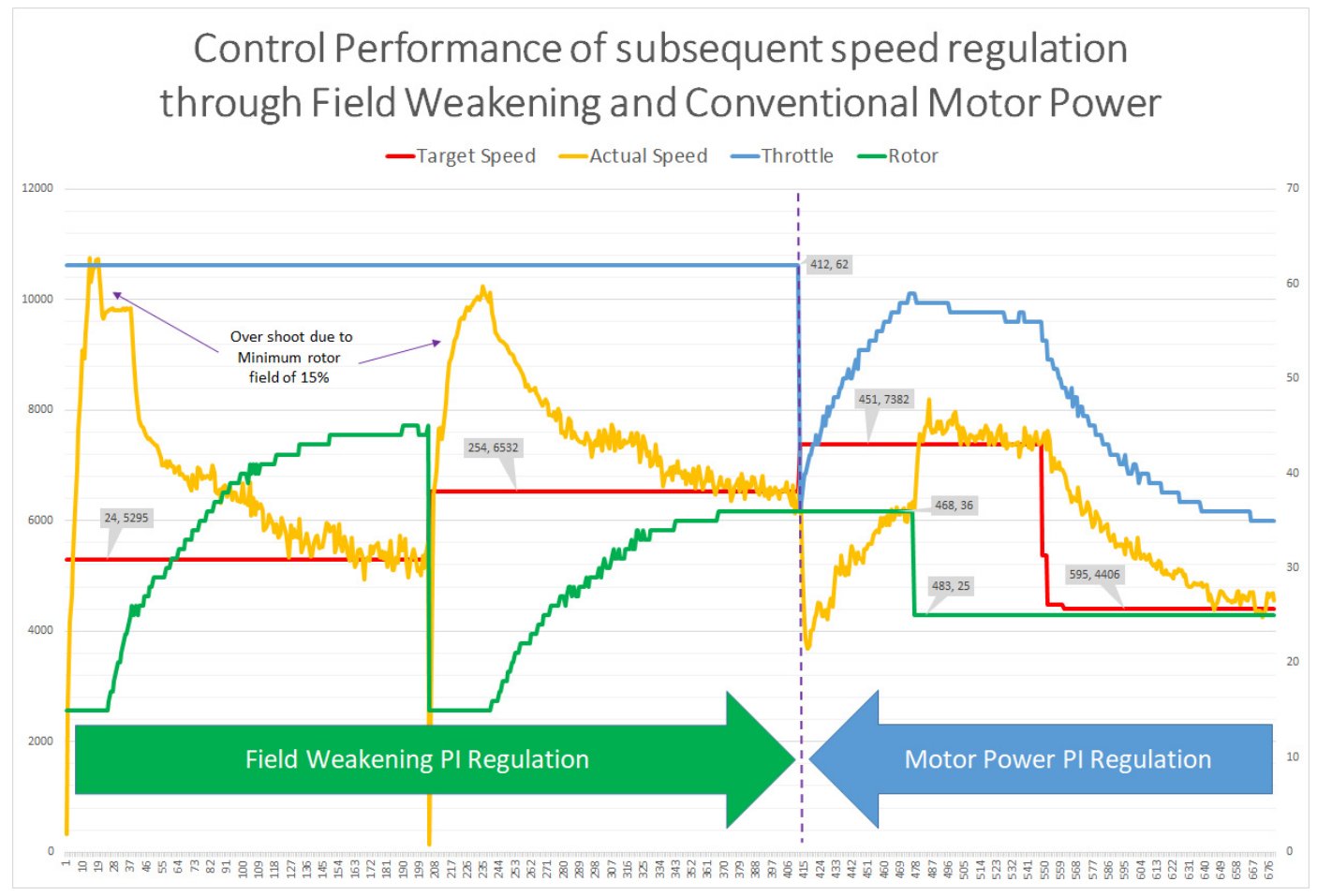

Figure 20. Control performance of subsequent speed regulation using field weakening and conventional motor power regulation

The overshoot condition that occurs in the early field weakening regulation is due to the fact that control values were cast to a minimum $15 \%$ PWM duty cycle to assure proper motor star-up hence but moderately overcome by the PI algorithm. Further, relatively large oscillations values in the vicinity of targeted speed shown are the effect of the low resolution uses in control system. In the future, it could be easily mitigated by increasing the control resolution to 12-bit the same as the one use in PWM generation.

\section{Conclusion}

The proposed Novel Electronic Speed Controller System for a Generator-Converted BLDC motor with field weakening has been found to provides satisfactory performance and providing basic information of the behavior of field weakening effect to BLDC motor. Further, the simple technic for converting Bosch 100A automotive generator into a BLDC motor with field weakening also was found to provides a viable method for doing the conversion. The tools and procedure developed for calibrating the installed hall sensor have also been found to mitigate the miss-alignment which might occur in sensor installation.

\subsection{Controller and Motor Performance}

The proposed control system together with the converted generator has demonstrates its capability in providing maximum power output for a wide range rotational speed and could be considered to be successful in approaching an ideal BLDC motor operation through field weakening technique. A relatively wide linear control range for rotor has been measured for the converted generator from $1.2 \mathrm{Volt}$ to $5.4 \mathrm{~V}$ rotor supply and has been tested with 3 different load scenario. Despite there is a minimum rotor supply needed for specific load, above those threshold level if has been found that the converted generator is able to produce maximum power in a wide range of speed confirming the effectiveness of ideal BLDC motor. Further, 39\% to $81 \%$ efficiency levels in various speed, rotor power and load scenario also confirmed that the converted generator performing up beyond brushed motor and better or in par with other BLDC [Aaron M. Harrington and Christopher Kroninger (2013)].

By observing the law of conservation of energy, one specific BLDC with field weakening could then either directed their power in unity, subject to their efficiency level, to produce large torque at low speed or to produce high speed at minimum torque. Maximum power of the motor also could be directed to one specific rotational speed by adjusting the rotor field removing the need for mechanical gearing therefore removing the mechanical 
losses associated with mechanical gear operation.

Further, due to real-time adjustment capability with immediate impact to torque and speed performance of such motor, the implementation of field weakening in BLDC motor for electric vehicle will offers a software based automatic transmission functionality without mechanical losses.

\subsection{Limitation and Future Research}

Despite the controller already uses a 12-bit PWM generation method, the fact that the current controller is still using low control resolution of 2 decimal digits feeds directly from the HMI modules degrades its control quality. Improving the control resolution especially for rotor field control into 12-bit resolution, like the one used by the PWM generation mechanism, will surely improve the control quality as well as control performance.

Although the current SPWM uses already provides smooth torque-ripple less operation is low commutation speed, improving it into SVPWM sinusoidal generation will offers better performance and smaller switching losses.

Both PI Rotor Control and PI Motor Control has demonstrated to works subsequently with seamless transition between both mode, however a combine regulation method of both Rotor and Motor control will surely improves the whole performance of the converted generator. A RPC connected external Artificial Intelligent based speed regulation running on CUDA powered micro-controller board, such as NVIDA jetson nano, might provide an advance speed regulation capability without any performance penalty.

\section{References}

Aaron M. Harrington \& Christopher Kroninger (2013). Characterization of Small DC Brushed and Brushless Motors, Army Reasech Laboratory (ARL).

Calin Capitan (2009). Torque Control in Field Weakening Mode, Institute of Energy Technology Aalborg University 2009.

Dura magnetic (2020). Magnetic Saturation: Understanding Practical Limitations to How Much Induced Magnetism Can Be Achieved in a Workpiece, Technical brief, retrieved Feb $5^{\text {th }} 2020$ from https://www.duramag.com/techtalk/tech-briefs/magnetic-saturation-understanding-limitations-to-induced-m agnetism-achieved-in-workpiece/

Hastanto SM Widodo, Suryadi Hermanto, Sarifuddin Madenda \& Lingga Hermanto (2020). Software based programmable IGBT IPM Dead-Time insertion module using 16-bit micro controller for BLDC motor control application with 3-phase Sinusoidal and Trapezoidal drive. Computer and Information Science, 13(2), https://doi.org/10.5539/cis.v13n2p1

Hong Zheng, Bo Wang \& Wuqiao Luo (2013). A Novel Field Weakening Control Strategy with Variable Reference Voltage for Asynchronous Motor, School of Automation Engineering, University of Electronic Science and Technology of China, Chengdu, China 2013.

Hong Zheng,Bo Wang \& Wuqiao Luo (2013). A Novel Field Weakening Control Strategy with Variable Reference Voltage for Asynchronous Motor, 3rd IFAC International Conference on Intelligent Control and Automation Science. September 2-4, 2013. Chengdu, China

Huazhang WANG (2011). Design and Implementation of Brushless DC Motor Drive and Control System, ELSEVIER 2011.

I Boldea (2005). Electric Generator Handbooks, Vol. 2, Variable Speed Generators, CRC Press, Boca Raton.

Jun Li, Qinruo Wang, Jiajun Yu \& Jianbin Xiong (2006). Field-weakening Control Algorithm for Interior Permanent Magnet Synchronous Motor Based on Space-Vector Modulation Technique. Journal of Convergence Information Technology, 8(3), https://doi.org/10.4156/jcit.vol8.issue3.20 2006.

Lee, S., Lemley, T. \& Keohane, G. (2009). A comparison study of the commutation methods for the three-phase permanent magnet brushless DC motor. In Electrical Manufacturing Technical Conference 2009: Electrical Manufacturing and Coil Winding Expo.

Lee, S., Lemley, T. \& Keohane, G. (2009). A comparison study of the commutation methods for the three-phase permanent magnet brushless DC motor. In Electrical Manufacturing Technical Conference 2009: Electrical Manufacturing and Coil Winding Expo. (Electrical Manufacturing Technical Conference 2009: Electrical Manufacturing and Coil Winding Expo).

Libor Prokop (2011). Using Motor Control eFlexPWM(mcPWM) for BLDC Motors, Freescale Semiconductor 
Application Note, Document Number: AN4429, 2011

Liu Zhen (2014). Sinusoidal Control of BLDCM with Hall Sensors Based on FRDM-KE04Z and Tower Board, Freescale Semiconductor Application Note, Document Number: AN4869 Rev. 0, 03/2014

Mitsubishi (1996). Mitsubishi semiconductors power modules mos, using intelligent power modules, Mitsubishi 1996

Pushek Madaan (2013). Brushless DC Motors - Part I: Construction and Operating Principles, EDN, retireved Feb $5^{\text {th }} 2020$ from https://www.edn.com/brushless-dc-motors-part-i-construction-and-operating-principles/

R.Babu Ashok \& B. Mahesh Kumar (2017). Comparitive Analysis of BLDC motor for different control topology, ELSEVIER 2017.

Waleed I. Hameed, Ahmed S. Kadhim, Ali Abdullah K. \& Al-Thuwaynee (2016). Field Weakening Control of a Separately Excited DC Motor Using Neural Network Optemized by Social Spider Algorithm, Scientific Research Publishing 2016

Wally Ripple (2007). Induction Versus DC Brushless Motors, retrieved Feb $5^{\text {th }} 2020$ from https://www.tesla.com/blog/induction-versus-dc-brushless-motors

Yasin Bektas, N. Fusun \& Oyman Sertelle (2011). Brushless direct current (BLDC) motor driving experimental set. Energy Education Science and Technology Part A: Energy Science and Research, 27(2), 455-466

\section{Copyrights}

Copyright for this article is retained by the author(s), with first publication rights granted to the journal.

This is an open-access article distributed under the terms and conditions of the Creative Commons Attribution license (http://creativecommons.org/licenses/by/3.0/). 